\title{
Healthcare Services: Patient Satisfaction and Loyalty Lessons from Islamic Friendly Hospitals
}

\author{
Muhammad Khalilur Rahman' \\ Miraj Ahmed Bhuiyan (1D) ${ }^{2}$ \\ Suhaiza Zailani ${ }^{3}$ \\ 'Faculty of Entrepreneurship and \\ Business, Universiti Malaysia Kelantan, \\ Pengkalan Chepa, I6I00, Malaysia; \\ ${ }^{2}$ School of Economics, Guangdong \\ University of Finance and Economics, \\ Guangzhou, Guangdong, People's \\ Republic of China; ${ }^{3}$ Faculty of Business \\ and Accountancy, University of Malaya, \\ Kuala Lumpur, Malaysia
}

Correspondence: Miraj Ahmed Bhuiyan School of Economics, Guangdong University of Finance and Economics, 21 Luntou Road, Guangzhou, Guangdong, People's Republic of China

Email ahmed.miraz@qq.com
Background: The study has aimed to investigate the Muslim patient's psychological factors related to healthcare services that influence their loyalty intention for further treatment at private hospitals in Malaysia.

Methods: Data were collected from private hospitals in Klang Valley. A total of 379 responses from patients were analysed using the structural equation modelling approach.

Results: The findings revealed that administrative behaviour, nurse's services and Shariah amenities have a highly significant impact on satisfaction. The healthcare technicality, hospital environment and physician's services have a significant relationship with patient satisfaction. Patient satisfaction has a significant impact on patient loyalty to healthcare services at the hospital. Administrative behaviour, physicians' services and healthcare technicality have a direct and positive relationship with loyalty intention, while Shariah amenity has a negative significant relationship with loyalty.

Conclusion: The results have important implications for product development and managerial considerations in hospitals. Service providers need to be mindful that all aspects, including Shariah amenities and generic healthcare service delivery, are important and need to be balanced and delivered satisfactorily to ensure customer satisfaction.

Keywords: Shariah amenities, medical service, patient satisfaction, patient loyalty, hospital

\section{Introduction}

The medical care service sector is facing continuous challenges while delivering services and demanding consistent quality performance. ${ }^{1}$ Duly, the medical field currently faces three prominent challenges: service integration, service quality and Internet-connected medical device security. While the medical providers promise to change healthcare service delivery forever, it will take some time before the advancements reach their full potential. Travers ${ }^{2}$ and Ebel $^{3}$ stated that patients have a multifaceted demand for healthcare services. Thus, medical care providers should maintain the service quality through delivering the desired medical care consistent with the current professional medical knowledge which consists of all the service quality components that confirm quality medical services beyond religious beliefs. ${ }^{4}$ This phenomenon also offers a unique opportunity to the medical care sector to deliver a new product, which is the Islamic perspective medical service. Islamic medical care service is a new mode of healthcare services, which aims to extend the reform of the Islamic medical care system for attracting Muslim patients. Past studies on this topic have focused mainly on the popular discourse of generic medical service quality. ${ }^{5-8}$ There has been little knowledge available focusing on the niche market of Islamic-friendly medical services quality, especially in the area of satisfaction and loyalty intention with medical services at private hospitals. 
In conjunction with this, the Malaysian government and private hospitals have taken the initiative to apply the Islamic-friendly concept to advise and patients on prayers and religious matters. ${ }^{9}$ New Straits Time reported that there are 55 major hospitals nationwide in Malaysia, which are part of the Muslim (Ibadah/worship) friendly hospital programme. Practicing medicine is not just a profession but is a social obligation, and this is the trust of the Islamic-friendly Hospital programme. Some Muslim healthcare workers are expected to provide the best care and service towards their patients and their community as they are seeking the pleasure of Allah SWT. ${ }^{10}$ Zawawi and Othman ${ }^{11}$ claimed that only a few hospitals offered Shariah-compliant services at the beginning of its introduction. Today, it is acknowledging that the number of hospitals certified with Shariah-compliant services is still few. ${ }^{12}$ However, according to SIRIM there are already 31 Shariah Compliant Institutions certified under MS 1900:2014, but the biggest number is in Islamic Institutions like Jabatan Pusat Zakat. For healthcare, most of the hospitals are commonly used the tag line of "Muslim/Ibadah/Halal Friendly Hospital" for the Islamic values even though they have not yet been certified with Shariah-compliant. ${ }^{10,12}$ Accordingly, due to the multidisciplinary scope of the subject matter, there exists confusion regarding "Islamic-friendly hospital", "Ibadah-friendly hospital" and "Halal-friendly hospital" terms.

One challenge faced by academicians and practitioners is to identify the right terminologies as well as the proper clarifications of the concepts. ${ }^{10}$ As a result, "Islamicfriendly", "Ibadah-friendly" and "Halal-friendly" terms, are often used interchangeably by academicians and practitioners since the concepts are similar. ${ }^{10,13}$ Nevertheless, according to, ${ }^{10}$ most of these definitions are loosely defined and have not fully served the Islamic law (Shariah). Thus, this study will be studying the "Islamicfriendly medical" that denotes an attempt by the hospitals to create the patient's experience enjoyable to Islamic values including allowing the patient to perform religious duties, while they are at the hospitals. The increasing trends in attitude towards Islamic values demonstrate how religion could be an appealing factor for the patient. Rahman and Zailani ${ }^{14}$ indicated that there is a supportive environment to the Islamic-friendly services in Malaysia for medical players to raise the value of their medical care. Given this situation, medical services quality from the Islamic perspective is an interesting issue to study.
Malaysia's private hospitals offer excellent diagnostic capabilities and provide patients with comfortable and private facilities. The private system is enhanced with investments from the medical tourism sector. ${ }^{15}$ Currently, many Malaysian private hospitals attempt to position themselves as medical service providers for Muslim patients by offering generic and Muslim-friendly medical care practices, products and services. ${ }^{14,16}$ Nevertheless, the market share of Islamic friendly medical services providers is negligible in Malaysia. For instance, only 26.73\% of private medical operators have been distinguished and perceived by the Ministry of Health as Muslim-friendly healthcare providers. ${ }^{16}$ These hospitals also have been facing a lot of difficulties and constraints in providing medical services to Muslim patients. ${ }^{17}$

\section{Literature Review}

This study has used the concept of confirmation or disconfirmation theory ${ }^{18}$ which focused on the customer's perception of satisfaction and loyalty intention. The theory also seeks to explain customer satisfaction as a function of customer perceived services for healthcare treatment. In this study, the concept of perceived service quality of healthcare is derived from the SERVQUAL model. ${ }^{19}$ The SERVQUAL model ${ }^{19}$ is accepted as the most valid, reliable and realistic approach to measuring service quality. Numerous models have been created in the service quality literature to measure the customers' psychological behavior of service quality. Parasuraman ${ }^{19}$ developed "the gaps' measure", which depends on comparing the consumers' perception of the service and their expectations of the offered service level, either satisfaction or dissatisfaction. Based on the concept of confirmation or disconfirmation theory and SERVQUAL model, this study investigates the additional SERVQUAL criteria (eg, Shariah amenities, physicians' services, nurses' services, healthcare technicality, hospital environment, administrative behaviour) for measuring customer satisfaction and their loyalty intention for further treatment at hospitals.

Shariah amenities consisted of Islamic concepts and practices. Shariah is derived from the sources of Islamic law (eg Al-Qur'an and Al-Hadith). Abdelkader ${ }^{20}$ and Rahman ${ }^{17}$ postulated that Shariah amenities consisted of the availability of prayer facilities, such as a prayer room with prayer mats and copies of Al-Qur'an, Islamic TV channels, an alcohol-free minibar, alternate single-sex spa facilities, female housekeeping and room staff, halal food, the direction of Makkah indicated in room, prayer times in local time zone, and maps showing locations of nearby 
mosques and locations of local halal restaurants. Generally, the physician's and nurse's sole objective is to help the patient. ${ }^{4}$ The character traits of the human and good physicians are embedded in the Al-Qur'an and Al-Hadith. As such, the Muslim physicians and nurses, guided by these two main sources of Islamic law, will possess the necessary character traits of virtuous physicians and nurses.

The use of various types of medical tools in this era makes medical facilities easier ${ }^{4}$ and more convenient for patients and doctors. Therefore, Islam allows having healthcare treatment in various ways unless the treatment is harmful, or the tools have such things which are not Shariah compliant. ${ }^{17}$ The hospital must guarantee a healthy and comfortable environment, which includes the provision for infection control, hygiene and personal wash and also provides clean water supply and good ventilation around the hospitals. ${ }^{4,1321}$ These facilities will confirm the prevention of harm for the patients and visitors to the hospital.

Administrative behaviour in hospitals plays a key role in providing quality medical care services. ${ }^{4,22}$ To improve administrative behaviour and efficiency, hospitals need to upgrade their medical-care process approaches from the manufacturing sector. ${ }^{23}$ For example, Toussaint ${ }^{24}$ and Radnor et al ${ }^{23}$ used a lean thinking approach in healthcare to ensure the quality of healthcare management in the hospitals. This approach is required to consider human factor paradigms ${ }^{25}$ and biotechnology for medical treatment safety, and socio-technical system aspects. ${ }^{26}$ The performance assessment in medical care is vital for both healthcare providers and patients because successful outcomes will equally be shared by all stakeholders in terms of satisfaction. Lyu et $\mathrm{al}^{27}$ and Rahman ${ }^{4}$ postulated that healthcare providers need to provide quality medical care for patient's satisfaction. As satisfaction is a key component, healthcare providers need to be aware of quality medical care and provide well-trained medical doctors. Tsai et $\mathrm{al}^{28}$ postulated that government policymakers have made patient's satisfaction a core measurable process to determine how doctor's facilities are assessed.

Based on the review of the literature, Figure 1 proposes the conceptual model of medical services quality for patient's satisfaction and their loyalty for further receive to healthcare service in private hospitals.

\section{Methodology}

\section{Measurement Instrument}

The measurement items were adapted from the previous studies. Shariah amenities were evaluated using eight items modified from ${ }^{12}$ and. $^{20}$ These items are used for healthcare services rendered in the hospitals in accordance with the Islamic friendly. To evaluate the physician's and nurse's services, fourteen questions were modified from. ${ }^{21,29,30}$ For measuring healthcare technicality, six items were adapted from Nurunnabi and Islam $^{31}$ and Alhassan et al. ${ }^{32}$ These items were considered for measuring the healthcare technicality as criteria for patient satisfaction and their loyalty intention for medical treatment at hospitals. The hospital environment refers to the sum of the elements and conditions in the hospital, which have an impact on patient through a good healthcare system, which is evaluated using seven items adapted from ${ }^{33}$ and. ${ }^{30}$ The administrative behaviour refers to the duties of administrative staff in the hospital which cover medical care systems, six items adapted from Dagger et $\mathrm{al}^{34}$ and Flannelly et al. ${ }^{35}$ Patient's satisfaction is the choice of perceived value toward medical care services related to physical, spiritual and emotional satisfaction, which was evaluated using 20 items modified from. ${ }^{17}$ Loyalty is the key to business success for an organization, and it is used in this study for evaluating patient loyalty for future medical treatment at hospitals using eight items adapted from, ${ }^{20,36}$ and..$^{33}$ A 7-point Likert scale ( $1=$ not applicable; ie, experience and judgment are not in favor), and (7 $=$ highly agree; ie, the evidence and judgment strongly favour one over the other) was used in this study to measure the respondents' view of medical care services, satisfaction, and loyalty intention. Vaus ${ }^{37}$ reported that the 7-point Likert scale could provide a wide choice of answers from the participants.

\section{Data Collection and Sample}

The questionnaires were distributed randomly to the Muslim patient at the selected fifteen Islamic-friendly private hospitals in Malaysia. The researcher only focused on adult patients from three hospital units. These were orthopaedic, surgery and medicine. Potential in-patients who came for a consultation on medical treatment were informed about the study and given the questionnaire. The non-probability random sampling technique was used for distributing and collecting questionnaires from Muslim patients in the hospitals. For outpatients, the respondents were chosen among those who had previously been hospitalised in hospitals. This ensured that the respondents had experience with services provided by the hospitals. To avoid the challenges that arise during data collection at each hospital, the first author of this study 


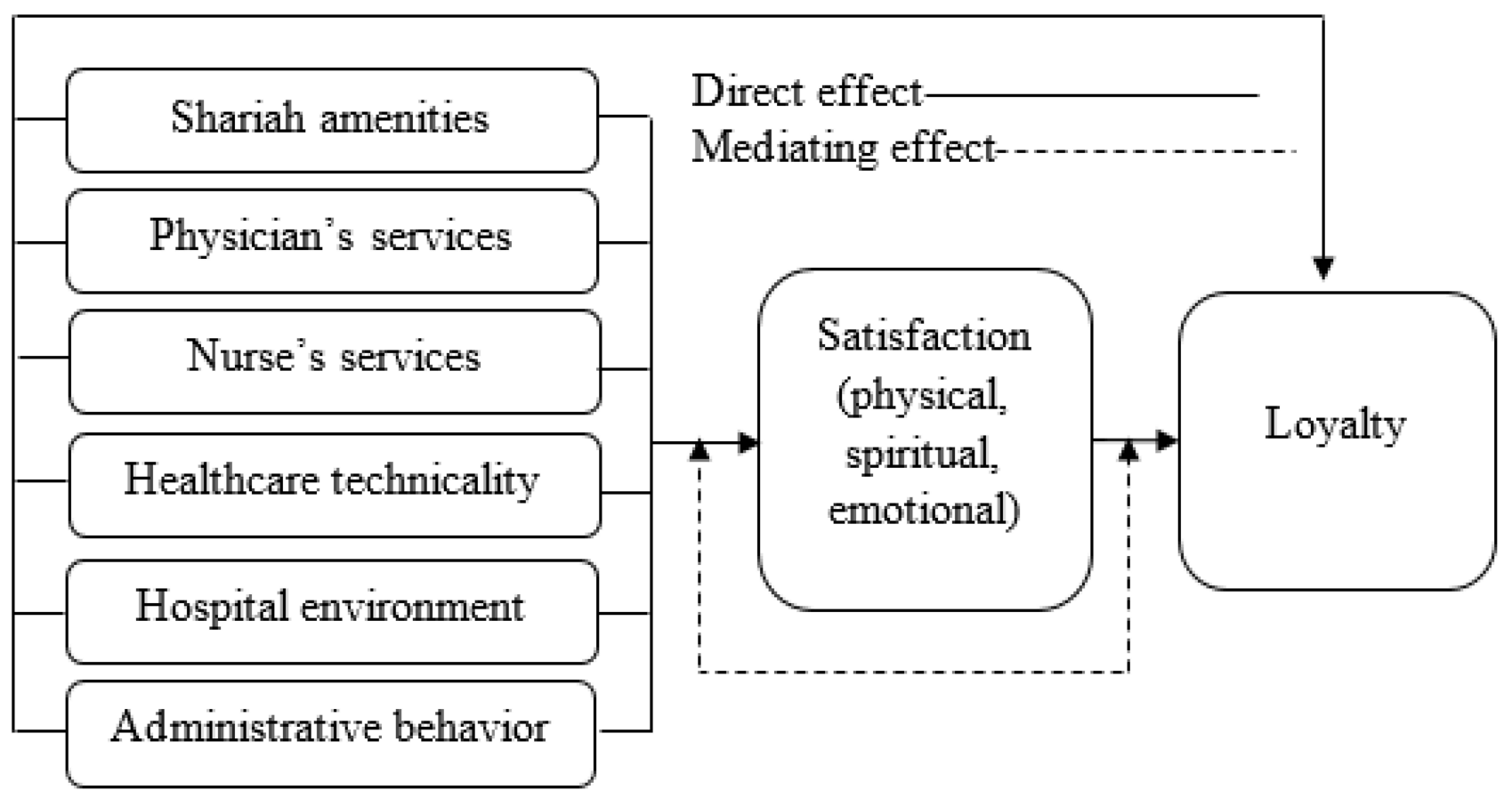

Figure I Conceptual model.

sought assistance from a medical administrative officer to distribute and collect the questionnaire. The medical administration officer introduced the researcher to the patients and explained the research. This quickened the data collection and helped ensure the data were collected from an appropriate sample. This technique was also used by Ahmed et $\mathrm{al}^{38}$ who claimed its advantage in terms of speedy distribution and attainment of more reliable responses.

Before collecting the data, an ethical research approval letter was obtained from the University Research Ethics Committee. An introductory letter was also obtained from the supervisory committee, which clearly expressed the reason for this study to acquire consent from the chosen hospitals for conducting the study. The self-distribution approach was used for collecting data from the respondents. Using the random sampling method, self-administered questionnaires with consent forms were distributed to patients in Muslim friendly hospitals, in two major areas of the Klang Valley. For each hospital, a medical administration officer was selected as an enumerator to distribute and collect the questionnaires. This helped in speeding up the data collection and obtaining answers in terms of gender, and ethnicity. The data collection process started in the first week of December 2018 and was completed in the first week of April 2019, taking more than six months to perform the task. We sent a consent form to the respondents whether they are willing to participate in this study. A total of 750 questionnaires with consent forms were physically distributed to Muslim patients in selecting fifteen Islamic friendly hospitals in Malaysia. Out of 750 questionnaires, we got return 507 responses, providing a return rate of $67.60 \%$. However, only 379 questionnaires were usable for data analysis with a response rate of $50.53 \%$.

For this study, fifteen Islamic friendly private hospitals were purposively selected from Klang Valley enclaves, in which ten hospitals are located in Selangor and five hospitals are located in Kuala Lumpur. There is no record of the total number of patients who have received medical services in the aforementioned surveyed hospitals; therefore, the questionnaires were distributed based on the size of the hospitals using the random sampling technique. The respondents were politely approached and requested to give their honest and truthful answers in completing the questionnaires, and they were ensured that their identities would be kept strictly confidential and would remain anonymous. The survey data were analysed in aggregate forms and used only for academic purposes. The sample size of this study was determined by using G*Power 3.1.9.2, as Faul et $\mathrm{al}^{39}$ suggested that it is one of the 
most suitable analytical software programs for a statistical test in the social and behavioural sciences. In selecting the seven predictors (based on the conceptual model), and power (1- $\beta$ error probability) of 0.99 , the result indicated that the minimum sample size could be 253 . Hence, the actual power was above 0.80 , indicating a satisfactory level of sample power. ${ }^{40}$

\section{Data Analysis Tool}

The structural equation modeling (SEM) statistical tool was applied to the AMOS 23.0 version to explore the relationship among the constructs. The main reason for using this statistical tool is that a measurement error can be assessed by the SEM, which performs a confirmatory factor analysis (CFA), causal relationship, path analysis and a covariance structural analysis. ${ }^{41}$ Following the statistical procedure of Sekaran and Bougie, ${ }^{41}$ and Hair et al,42 this study examined the measurement model and a structural model. The SEM has a higher analyzing ability to check measurement errors, nonlinearities, correlated error terms, modelling interactions and dependent/independent relationships, thus, this study used the SEM technique.

\section{Results and Analysis Demographic Analysis}

The respondents' profile was analyzed based on the 379 respondents' relevant responses, 52.2\% were females, whilst $47.8 \%$ were male patients. Table 1 shows in detail the respondent's information.

\section{Measurement Model Analysis}

The findings of the measurement model show satisfactory results. For example, the root-mean-square error of approximation (RMSEA) $=0.048$, goodness-of-fit index $(\mathrm{GFI})=0.828$, adjusted goodness-of-fit index $(\mathrm{AGFI})=$ 0.803 , normed fit index $(\mathrm{NFI})=0.865$, Incremental Fit Index $(\mathrm{IFI})=0.932$, tucker-Lewis index $(\mathrm{TLI})=0.925$, comparative fit index $(\mathrm{CFI})=0.931$, Parsimony Standard Adjustment Index $(\mathrm{PNFI})=0.788$, and Parsimonious comparative fit index $(\mathrm{PCFI})=0.849$. Moreover, the Hoelter's critical N' for 0.5 and 0.01 levels was above 200 indicating that the sample was adequate. The standard regression weights of the model were above 0.50 indicating convergent validity. Construct reliability consists of a composite reliability (CR) and an average variance extracted (AVE). In this study, factors loading of all items were greater than
0.65 , indicating a satisfactory level of convergent validity. The range of CR values was $0.86-0.91$ with a cut-off point $\geq 0.60$ and AVE values of $0.52-0.71$ with a threshold value $\geq 0.50$. Bourgeois et $\mathrm{al}^{43}$ discussed an AVE threshold value of 0.50 and $\mathrm{CR}>0.60$. Thus, the construct reliability was achieved for the measurement model. Byrne ${ }^{44}$ stated that the values of the CR and the AVE were the key components to measure the construct reliability and convergent validity. To measure the discriminant validity, this study ran the measurement model by linking all the independent and the dependent variables together to examine whether the constructs were highly correlated. Thungjaroenkul et $\mathrm{al}^{45}$ indicated that if the correlation value between the two constructs exceeded 0.85 , the discriminant validity could not be attained. The results indicated that all values of the constructs are below the threshold value of $<0.85$, and it was ensured that the discriminant validity was achieved for the measurement model (Table 2). A summary of measurement analysis results is shown in Figure 2 and Table 2.

\section{Structural Model Analysis}

The results indicated that the $\mathrm{R}^{2}$ value for the endogenous variable of the patient's satisfaction was 0.54 , indicating the contribution of constructs to the Shariah amenities, physicians' services, nurses' services, healthcare technicality, hospital environment and administrative behaviour in estimating the patient's satisfaction, which was $54 \%$. Similarly, the $\mathrm{R}^{2}$ value was 0.73 indicating the contribution of the construct to the overall patient's satisfaction in estimating the patient loyalty for medical treatment, which was $73 \%$. Figure 3 shows the results of structural model analysis for patient healthcare loyalty at hospital.

The study found a positive relationship between Shariah amenities and patients' satisfaction and was significant at $\mathrm{p}<0.01(\beta=0.0 .246$, C.R. $=4.472)$, indicating that Shariah amenities influence patient satisfaction. Therefore, H1a was accepted. The statistical analysis found a significant relationship of beta coefficient $(\beta=$ 0.279 and C.R. $=3.770$ ). This finding signifies that physicians' services quality has a direct effect on Muslim patients' satisfaction, thereby, H1b is accepted. There is a positive relationship between nurses' services quality and Muslim patient satisfaction and it was statistically significant $(\mathrm{p}<0.05, \beta=0.338$, and C.R. $=4.970)$, and $\mathrm{H} 1 \mathrm{c}$ is accepted. The study found a positive relationship between healthcare technicality and patients' satisfaction and was statistically significant at $\mathrm{p}<0.01$ with $\beta=0.393$, 


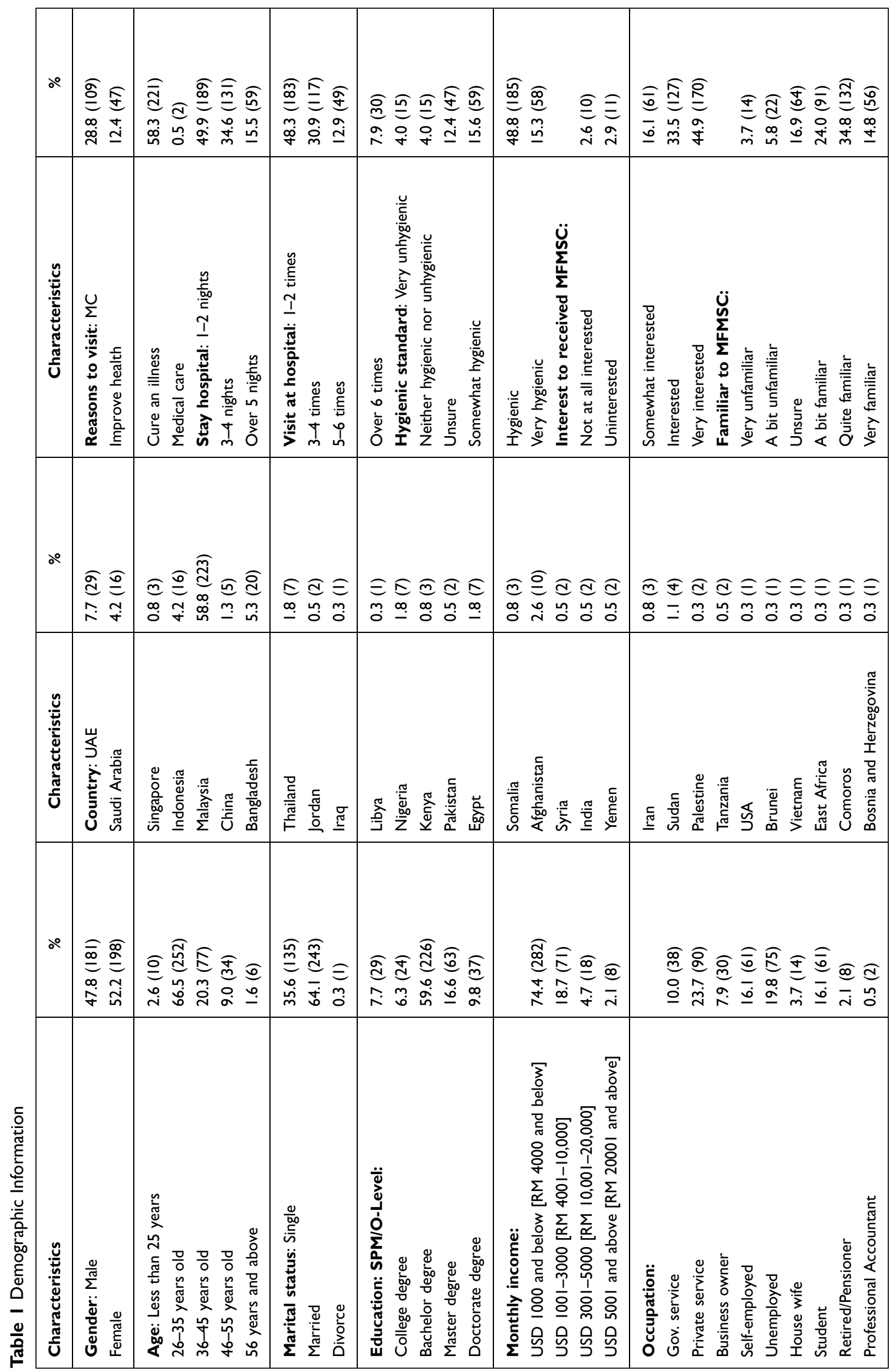


Table 2 Convergent Validity

\begin{tabular}{|c|c|c|c|}
\hline Characteristics & Loading & AVE & CR \\
\hline Shariah Amenities & & 0.58 & 0.87 \\
\hline [SAI] The hospital provides a copy of the Holy Quran in the prayer room & 0.70 & & \\
\hline [SA3] The hospital provides halal foods and drinks & 0.68 & & \\
\hline [SA4] The hospital provides a prayer room for each ward for patients & 0.83 & & \\
\hline [SA5] The hospital provides prayer amenities (times [Azan], mats, direction of Qibla, wudhu) in the prayer room & 0.81 & & \\
\hline [SA7] The hospital provides an ablution pipe for solat purpose & 0.79 & & \\
\hline Physicians' Services & & 0.59 & 0.88 \\
\hline [PQI] Physicians inform me regarding the use of vaccines that are porcine in origin & 0.69 & & \\
\hline [PQ3] Physicians respond promptly to my request & 0.82 & & \\
\hline [PQ4] Physicians understand my specific problem & 0.84 & & \\
\hline [PQ5] Physicians are very sympathetic towards me & 0.74 & & \\
\hline [PQ6] Physicians respect my privacy & 0.74 & & \\
\hline Nurses' Services & & 0.66 & 0.89 \\
\hline [NQ2] Nurses are ever willing to help me & 0.82 & & \\
\hline [NQ3] Nurses respond promptly to my request & 0.85 & & \\
\hline [NQ4] Nurses respect Islamic values and principles & 0.82 & & \\
\hline [NQ5] Nurses are very sympathetic towards me & 0.77 & & \\
\hline Healthcare Technicality & & 0.52 & 0.86 \\
\hline [TQI] This hospital uses up-to-date equipment & 0.61 & & \\
\hline [TQ2] This hospital provides service on time & 0.74 & & \\
\hline [TQ3] This hospital fulfils the promised service at the promised time & 0.76 & & \\
\hline [TQ4] This hospital keeps accurate records and documents & 0.74 & & \\
\hline [TQ5] This hospital has adequate of consulting rooms & 0.77 & & \\
\hline [TQ6] This hospital provides a stable amenities (eg water and electricity) & 0.70 & & \\
\hline Hospital Environmental & & 0.64 & 0.90 \\
\hline [EII] This hospital has a clean and hygienic appearance & 0.80 & & \\
\hline [EI2] The waiting room of this hospital is pleasant & 0.84 & & \\
\hline [EI3] The surrounding area of this hospital is quiet & 0.73 & & \\
\hline [EI4] The rooms of this hospital are pleasant & 0.86 & & \\
\hline [EI5] This hospital is located in a safe and secure place & 0.76 & & \\
\hline Administrative Behaviour & & 0.60 & 0.88 \\
\hline$[A B I]$ The administrative procedures of this hospital are (paper work and paying of bills) fast and easy & 0.67 & & \\
\hline [AB2] The administrative staff of this hospital respect my concerns & 0.79 & & \\
\hline [AB3] The administrative staff of this hospital are courteous & 0.79 & & \\
\hline [AB5] The administrative staff of this hospital are treating me with respect and dignity & 0.80 & & \\
\hline [AB6] Overall, I have confidence in this hospital's administrative system & 0.82 & & \\
\hline Physical Satisfaction & & 0.71 & 0.91 \\
\hline [PSI] I am satisfied with the medical treatment provided in this hospital & 0.86 & & \\
\hline [PS2] I am satisfied with the feeling of security in receiving treatment here & 0.86 & & \\
\hline [PS3] I am satisfied with the physicians who treated me & 0.87 & & \\
\hline [PS4] I am satisfied with the nurses who treated me & 0.77 & & \\
\hline Emotional Satisfaction & & 0.68 & 0.86 \\
\hline $\begin{array}{l}\text { [ES3] Medical professionals in this hospital help me to overcome my fears/concerns on the outcome of medical } \\
\text { treatment }\end{array}$ & 0.88 & & \\
\hline [ES4] Medical professionals in this hospital give me credible hope or encouragement & 0.89 & & \\
\hline [ES6] Medical professionals in this hospital listen to my fears, hopes, pain and dreams & 0.68 & & \\
\hline
\end{tabular}

(Continued) 
Table 2 (Continued).

\begin{tabular}{|c|c|c|c|}
\hline Characteristics & Loading & AVE & CR \\
\hline Spiritual Satisfaction & & 0.70 & 0.90 \\
\hline [SSI] Medical professionals in this hospital pray for me for my health and rapid recuperation. & 0.74 & & \\
\hline [SS3] Medical professionals in this hospital recite "bismillah" before my medical procedure & 0.84 & & \\
\hline [SS4] Medical professionals in this hospital help me to appreciate Allah cares for people whom I love & 0.90 & & \\
\hline [SS5] Medical professionals of this hospital actively address my other spiritual needs (trust, faith, love to Allah) & 0.86 & & \\
\hline Patient Loyalty & & 0.56 & 0.88 \\
\hline$[I R I]$ I intend to revisit this hospital because of ease inaccessibility to treatment & 0.77 & & \\
\hline [IR2] I intend to revisit this hospital because of its Islamic-friendly medical quality service & 0.82 & & \\
\hline [IR3] I intend to revisit this hospital because healthcare professionals are consistently courteous and respectful to me & 0.84 & & \\
\hline [IR4] I intend to continue to use this hospital for its Islamic-friendly healthcare practices & 0.77 & & \\
\hline $\begin{array}{l}\text { [IR5] I intend to revisit this hospital because the physicians are aware of the presence of potentially non-Halal } \\
\text { ingredients in medicines }\end{array}$ & 0.61 & & \\
\hline [IR8] I intend to revisit this hospital because of precise and clear explanations of my treatment results & 0.65 & & \\
\hline
\end{tabular}

C.R. $=4.415$, and p-value $=0.000$, thereby, H1d is accepted. A positive relationship was found between environmental infrastructure services quality and Muslim patients' satisfaction and was statistically significant at $\mathrm{p}=$ 0.004 level with $\beta=0.331$, and C.R. $=3.848$, and thus H1e was accepted. The findings also showed a positive strong relationship between the two constructs and was significant at $\mathrm{p}<0.01$ with $\beta=0.544$, and C.R. $=7.064$. Therefore, H1f was accepted.

Hypothesis $\mathrm{H} 2 \mathrm{a}$ predicts that Shariah amenities have a significant negative effect on loyalty intention for medical treatment. The hypothesis was accepted with a negative relationship of $\beta$ coefficient $=-0.202$ and $C$. $\mathrm{R}$. $=-2.845$ with $\mathrm{p}$-value $=0.031$, therefore, $\mathrm{H} 2 \mathrm{a}$ is accepted. Hypothesis H2b predicted that physicians' services have a significant effect on Muslim patient loyalty intention for medical treatment $(\beta$ coefficient $=0.270$ and C.R. $=3.913$ and $\mathrm{p}$ value $=0.002$ ). Hypothesis H2c predicted that nurses' services have positive a significant effect on Muslim patients' loyalty intention for medical treatment. The statistical analysis found a negative and insignificant relationship of $\beta$ coefficient $=-0.083$ and $\mathrm{C}$. $\mathrm{R}$. $=-1.886$ and $\mathrm{p}$-value $=0.106$. Therefore, $\mathrm{H} 2 \mathrm{c}$ is not significant. Hypothesis $\mathrm{H} 2 \mathrm{~d}$ predicted that healthcare technicality has a positive significant effect on Muslim patients' loyalty intention for future medical treatment. Statistical analysis also discovered a significant positive relationship, $\beta$ coefficient $=0.320$, C.R. $=3.903$, and $\mathrm{H} 2 \mathrm{~d}$ is accepted. Hypothesis H1e predicted that the hospital environment has a positive significant effect on Muslim patients' loyalty intention for medical treatment ( $\beta$ coefficient $=-0.094$, and C.R. $=1.068$ ); therefore, H1e is not significant. There is a significant relationship between the two constructs, administrative behaviour and the Muslim patients' loyalty intention for medical treatment, and it was statistically and positively significant at $\mathrm{p}<0.01$ with $\beta$ coefficient $=0.289$, and C.R. $=3.010$, thereby, $\mathrm{H} 2 \mathrm{f}$ is accepted. $\mathrm{H} 3$ illustrated the path from Muslim patients' satisfaction to Muslim patient loyalty for medical treatment was positively significant at $\mathrm{p}<$ 0.01 with $\beta=0.755$, and C.R. $=8.206$, therefore, H3 is accepted (Table 3$)$.

According to the results of Table 4, the statistical analysis found a significant path coefficient $\beta$ for $\mathrm{X}-\mathrm{M}(\mathrm{a})=0.515, \mathrm{M}-\mathrm{Y}(\mathrm{b})=0.764$, and an insignificant direct path $\mathrm{X}-\mathrm{Y}(\mathrm{c})=-0.031$ at a significant level of $1 \%$ with $\mathrm{p}<0.01$. The results of Sobel's statistical test were 5.740 with the proportion of mediation being 0.927 . Thus, it could be concluded that the relationship between Shariah amenities and patient's loyalty for medical treatment was fully mediated by patients' satisfaction. The mediating role of patients' satisfaction was tested for the relationship between physicians' services and patient loyalty for medical treatment. The statistical analysis found a significant path coefficient for X-M (a) $=0.543, \mathrm{M}-\mathrm{Y}(\mathrm{b})=0.714$, and a direct path $\mathrm{X}-\mathrm{Y}(\mathrm{c})=0.125$ with the proportion of mediation $=0.756$.

From the statistical analysis, it was found that a significant path coefficient for X-M (a) $=0.577$, $\mathrm{M}-\mathrm{Y}(\mathrm{b})=0.727$, and a direct path X-Y (c) $=0.096$ at the significant level of $1 \%(p<0.01)$, with the result of Sobel's test statistics $=4.739$ and the proportion of 


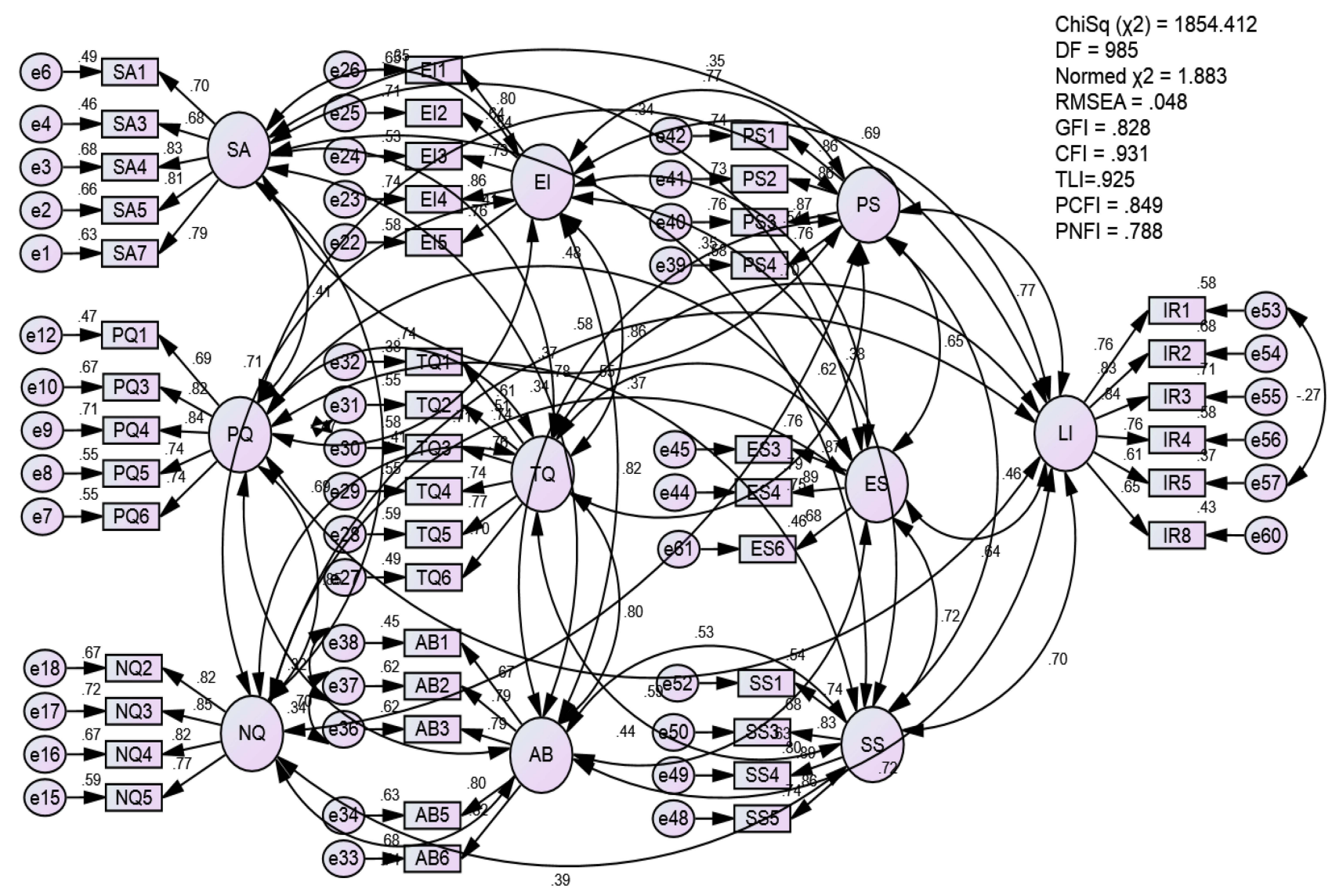

Figure 2 Measurement model.

Abbreviations: SA, Shariah amenities; PQ, physician's services; NQ, nurse's services; TQ, healthcare technicality; El, hospital environment; AB, administrative behaviour; PS, physical satisfaction; ES, emotional satisfaction; SS, spiritual satisfaction; Lo, loyalty.

mediation $=0.814$. The findings specified a significant direct relationship between nurses' services and patients' loyalty for medical treatment, with a significant Sobel $Z$ test result of 4.739 , with $Z \geq 2.58$. Similarly, patient satisfaction mediates the effect of healthcare technicality, hospital environment, and administrative behavior on patient loyalty. Table 4 shows the summary results of mediating effect.

\section{Discussion}

The findings indicate there is a significant relationship between Shariah amenities and patient's satisfaction but there is a significant negative relationship between Shariah amenities and patient loyalty. The indication echoes the findings of previous studies. ${ }^{6,16,17,46,47}$ Rahman et $\mathrm{al}^{17}$ identified the positive significant link between Shariah amenities and satisfaction but there is no available study that examined the direct relationship between Shariah amenities and loyalty. Thus, this is the first to examine the direct negative relationship between
Shariah amenities and loyalty. Previous literature indicated the importance of the physician's role in enhancing patient satisfaction with medical care services. ${ }^{14,48,49}$ Muslim patients looked for medical care, friendliness, and religious-oriented affinity, and supportive empathy, helpful and attentive physicians. This study found that physicians' medical services quality had a significant relationship with Muslim patient satisfaction. The statistical analysis indicated a significant positive relationship between nurses' services and patient's satisfaction. This finding contradicts the previous study by Rahman and Zailani ${ }^{13}$ which identified nurse's medical care practices have no significant relationship with satisfaction; however, Benzimra et $\mathrm{al}^{50}$ and $\mathrm{Celik}^{51}$ found there is a significant relationship between service quality, nurse services and satisfaction. Although most patients cannot evaluate the healthcare technicality of a hospital's service quality in terms of technical accuracies and procedures, ${ }^{52,53}$ the statistical findings showed that Muslim patient's satisfaction was also highly dependent 


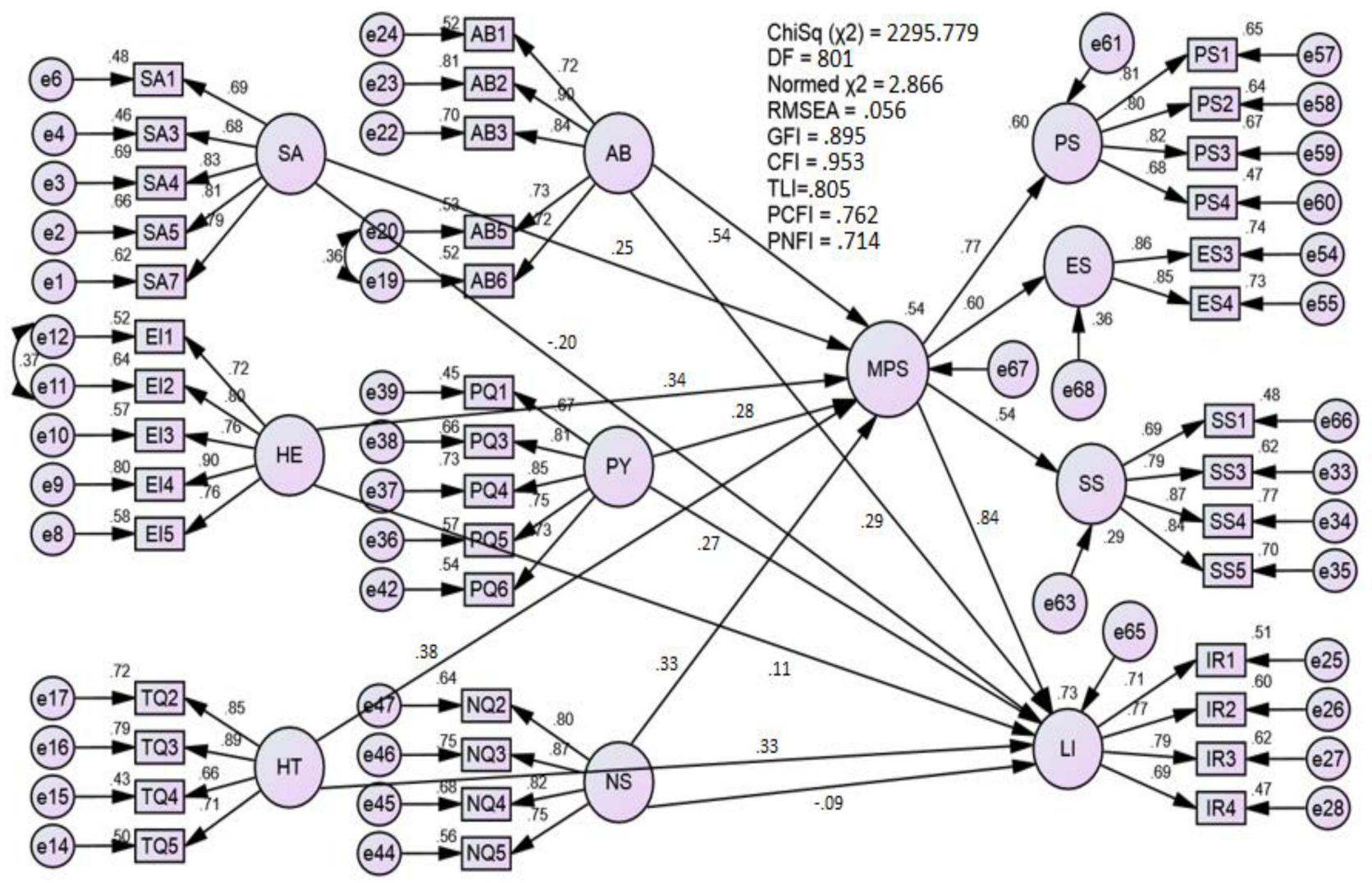

Figure 3 Structural model.

on healthcare technicality of the hospital. It is expected as the development of medical care services requires healthcare technicality services for a satisfactory treatment at the hospital. This finding supports the study by Rose et al, ${ }^{54}$ Zullig et al, ${ }^{55} \mathrm{Sim}$ and Lee, ${ }^{56}$ who indicated that healthcare technicality is the most important aspect of hospital services.

There is a significant relationship between hospital environment and patient satisfaction. This finding is related to the previous studies. ${ }^{4,53,56}$ The hospital may

Table 3 Path Coefficient

\begin{tabular}{|l|c|c|c|c|c|c|c|c|}
\hline Hypo & \multicolumn{3}{|c|}{ Relation } & Estimate & S.E. & C.R. & P & Comment \\
\hline HIa & PS & $<-$ & SA & 0.246 & 0.055 & 4.472 & 0.000 & Significant \\
HIb & PS & $<-$ & PY & 0.279 & 0.074 & 3.770 & 0.000 & Significant \\
HIc & PS & $<-$ & NS & 0.338 & 0.068 & 4.970 & 0.000 & Significant \\
HId & PS & $<-$ & HT & 0.393 & 0.089 & 4.415 & 0.000 & Significant \\
HIe & PS & $<-$ & HE & 0.331 & 0.086 & 3.848 & 0.004 & Significant \\
HIf & PS & $<-$ & AB & 0.544 & 0.077 & 7.064 & 0.000 & Significant \\
H2a & LO & $<-$ & SA & -0.202 & 0.071 & -2.845 & 0.03 I & Significant \\
H2b & LO & $<-$ & PY & 0.270 & 0.069 & 3.913 & 0.002 & Significant \\
H2c & LO & $<-$ & NS & -0.083 & 0.044 & -1.886 & 0.106 & Not Significant \\
H2d & LO & $<-$ & HT & 0.320 & 0.082 & 3.902 & 0.003 & Significant \\
H2e & LO & $<-$ & HE & 0.094 & 0.088 & 1.068 & 0.235 & Not Significant \\
H2f & LO & $<-$ & AB & 0.289 & 0.096 & 3.010 & 0.012 & Significant \\
H3 & LO & $<-$ & MPS & 0.755 & 0.092 & 8.206 & 0.000 & Significant \\
\hline
\end{tabular}

Notes: Significant level $p \leq 0.01,0.05$.

Abbreviations: Hypo, hypotheses; SE, standard estimation; CR, critical ratio; PS, patient's satisfaction; SA, Shariah amenities; PY, physician's services; NS, nurse's services; $\mathrm{HT}$, healthcare technicality; $\mathrm{HE}$, hospital environment; $A B$, administrative behaviour; LO, loyalty. 
Table 4 Mediating Effects

\begin{tabular}{|l|c|c|c|c|c|c|c|c|c|c|c|}
\hline Hyp. & $\mathbf{X}$ & $\mathbf{M}$ & $\mathbf{Y}$ & $\mathbf{X - M}(\mathbf{a})$ & $\mathbf{M}-\mathbf{Y}(\mathbf{b})$ & $\mathbf{X}-\mathbf{Y}(\mathbf{c})$ & $\mathbf{S E a}$ & $\mathbf{S E b}$ & Sobel Z & PM & Comments \\
\hline H4a & SA & MPS & LI & 0.515 & 0.764 & 0.031 & 0.089 & 0.017 & 5.740 & 0.927 & Full mediation \\
H4b & PY & MPS & LI & 0.543 & 0.714 & 0.125 & 0.131 & 0.017 & 4.125 & 0.756 & Partial mediation \\
H4c & NS & MPS & LI & 0.577 & 0.727 & 0.096 & 0.121 & 0.017 & 4.739 & 0.814 & Partial mediation \\
H4d & HT & MPS & LI & 0.610 & 0.691 & 0.149 & 0.139 & 0.018 & 4.360 & 0.738 & Partial mediation \\
H4e & HE & MPS & LI & 0.634 & 0.699 & 0.131 & 0.117 & 0.018 & 5.367 & 0.772 & Partial mediation \\
H4f & AB & MPS & LI & 0.696 & 0.679 & 0.147 & 0.121 & 0.020 & 5.67 I & 0.763 & Partial mediation \\
\hline
\end{tabular}

Abbreviations: Hyp, hypothesis; PM, proportion of mediation.

improve its environment by encouraging all staff members to be friendly with their patients. This effort can increase patient satisfaction levels. Good hospital policies (eg control of room temperature, lighting, implementing quiet hours or installing sound-absorbing materials in busy hospital areas, such as nursing places) may also have an effect on hospital environments. When patients feel more comfortable, they may be more likely to have better rest and recover more quickly. Staff's effort to maintain cleanliness and follow safety protocol can also increase patients' satisfaction.

The statistical results identified a significant relationship between administrative behaviour and Muslim patient's satisfaction. This finding is relevant to the previous studies that have developed a relationship between medical personnel behaviour and patient's satisfaction. ${ }^{51,53,56,57}$ The administrative behaviour is related to how medical staff (specialist physicians, nurses and administrative staff) behave with the patients. Patients' behavioural intention is influenced by their satisfaction in receiving medical services at hospitals. This study examines and finds that there is a significant link between patient satisfaction and loyalty for future medical treatment at hospitals in Malaysia. This result is related to the previous studies highlighted on patient's satisfaction, preferences, adherence, and loyalty towards medical care services at the hospital. ${ }^{58-61}$ The structural model demonstrates that there is a highly significant relationship between Muslim patient satisfaction and their loyalty. As noted by $\mathrm{Wu}$ et al, ${ }^{62}$ Muslim patients are more likely to revisit the hospitals for future medical treatment once they are satisfied with their medical services.

The study believed that the investigations on the relationships of medical services quality are different from the previous studies. The study has confirmed with the Standard and Industrial Research Institute of Malaysia (SIRIM) and experts that this study is considered new as no one has tested the ${ }^{12}$ on Islamic friendly services requirement and Shariah-based quality management systems requirements in the context of hospitals. Therefore, in terms of significance and contributions, it is believed that this study can justify its significance why it needs to be conducted. The significant and insignificant findings are beyond the control of the study as long as the study has justified the reasons behind those findings; it is believed to be significant.

The study found one full mediation and five partial mediation relationships of Muslim patient satisfaction in the relationship between the Islamic friendly medical services quality and Muslim patient loyalty for future medical treatment. Muslim patient's satisfaction fully mediates the relationship between Shariah amenities and Muslim patient's loyalty. Besides, the study found a partial mediation relationship of Muslim patient's satisfaction among physician's services, nurse's services, healthcare technicality, hospital environment and administrative behaviour with loyalty. This finding implies that the path from physician's services to Muslim patient's satisfaction is a critical route to influence patient's loyalty for future medical treatment at Malaysian hospitals. Based on the findings, it is indicated that Muslim patient satisfaction plays a critical mediating role in influencing the relationships between the criteria of Islamic friendly medical services quality and Muslim patient's loyalty for medical treatment. The particulars of each mediation relationship are discussed in the following sub-sections. The above result is consistent with, ${ }^{62}$ who found the mediating role of satisfaction in the relationship between a hospital brand image and loyalty.

\section{Conclusion}

This study has a significant theoretical and knowledge contribution, which shows the aspects of Islamic friendly medical services quality, which influence patient's satisfaction and loyalty. Shariah amenities have a significant relationship with loyalty through the satisfaction of Muslim patients. Although Shariah amenities have a positive relationship with satisfaction, surprisingly, it has a negative relationship 
with loyalty for future medical treatment at hospitals. Some researchers used Shariah amenities in different contexts and found that Shariah amenities are important for Muslim consumers when deciding to purchase different products and services. In the aspect of medical services quality for Muslim perspective, this study revealed all aspects of Islamic friendly medical services quality - administrative behaviour, nurses' services, healthcare technicality, hospital environment and physicians' services - have a relationship with satisfaction. Patients can judge hospital services quality, especially through the physicians, nurses, hospital environment services and administrative behaviour. As patients' judgment is a core aspect of quality care, physicians and nurses should be careful to provide the expected service to the patients. Although the hospital environment is important for patient's satisfaction, it is not considered important when deciding to revisit the hospital in the future. Besides, healthcare technicality influences patients' satisfaction and loyalty among Muslim patients at the hospitals.

The findings provide a basis for managerial and marketing recommendations in the development of quality medical services for Muslim patients. Hospital managers need to understand and provide Islamic friendly medical services that ensure patients' satisfaction and stimulate loyalty for future usage of medical treatment. Note that managers at the hospital need to be mindful while adopting Shariah amenities. This criterion is a necessary but not the only aspect of quality medical service in Islamic friendly medical hospitals. Muslim patients prefer to see the Shariah amenities along with other service quality criteria such as nurse's services, physician's services, healthcare technicality, hospital environment, and administrative behaviour while receiving medical treatment. Perhaps, the most significant observation of this study is that despite the significant positive relationship between Shariah amenities and patient's satisfaction, its relationship with loyalty is negative. Thus, hospital marketing departments need to be mindful and understand when promoting Shariah amenities, as its excessive promotion might be counter-productive in attracting future patients.

The main limitation of this study is that the research participants were only Muslim patients who were recovering from health ailments. Many who were rather ill were not willing to answer the questionnaire. Usually, patients were in a hurry to meet their physicians, and some had a limited understanding of the English language. Many were unable to answer the questionnaires. The researcher did not insist on everyone being selected at the location to answer the questionnaire. Most patients who responded to the questionnaire had sufficient fitness physically and mentally to answer the questionnaire. The measurement of patient's satisfaction was based on the perceptual scales, which may not be as precise as the objective scales. Perceptual scales are usually subjected to the respondent's bias, whereas the objective scales acquire more quantifiable data. Being a social scientist, the researcher is only familiar with the perceptual scale. The real scale could be more effectively measured by scientists, such as medical doctors themselves.

Future research should take into consideration expanding the study on public hospitals, clinics and health centres with a view to extracting the common dominating factors of interest. With larger samples from the public hospitals, the findings are expected to provide a more accurate picture of the services, and they could be generalized as representing Islamic medical services provision in Malaysia. Comparative research can also be undertaken to assess the differences in medical services quality from the Islamic perspective, satisfaction and their loyalty to medical treatment in the Malaysian public hospitals and the private healthcare providers. Such an investigation is important to keep track of the country's development towards sustainability, which is presently the national agenda in Malaysia. Patient's friends and family members' perceptions may also represent a potential study area as these groups could become the key influencers of patients' medical care choices.

\section{Ethical Statement}

We confirm that all participants were informed about the purpose of the study, in accordance with the Declaration of Helsinki.

\section{Acknowledgments}

We would like to thank the university authorities for granting approval for this study; the authors of the academic scales for allowing us to use their data collection tools and scales.

\section{Disclosure}

The authors report no conflicts of interest in this work.

\section{References}

1. Büyüközkan G, Çifçi G. A combined fuzzy AHP and fuzzy TOPSIS based strategic analysis of electronic service quality in healthcare industry. Expert Syst Appl. 2012;39:2341-2354. 
2. Travers JL, Le C, Desai MM, Merrill JA. Factors associated with dissatisfaction in medical care quality among older medicare beneficiaries suffering from mental illness. J Aging Soc Policy. 2021;33 (1):51-66. doi:10.1080/08959420.2019.1628624

3. Ebel T, Larsen E, Shah K. Strengthening health care's supply chain: a five-step plan; 2013. Available from: http://www.mckinsey.com/ insights/health_systems_and_services/strengthening_health_cares supply_chain_a_five_step_plan. Accessed March 23, 2019.

4. Rahman MK. Medical tourism: tourists' perceived services and satisfaction lessons from Malaysian hospitals. Tour Rev. 2019;74 (3):739-758. doi:10.1108/TR-01-2018-0006

5. Vanichchinchai A. An analysis of hospital characteristics on lean and service quality. Int J Lean Six Sigma. 2021;ahead-of-print(ahead-ofprint). doi:10.1108/IJLSS-07-2020-0107

6. Rahman MK, Newaz MS, Hemmati M, Mallick SY. Analyzing health-care service environment with Malaysian general practice clinics. Health Educ. 2021;121(3):246-264. doi:10.1108/HE-102020-0106

7. Maurice-Szamburski A, Michel P, Loundou A, Auquier P. Validation of the generic medical interview satisfaction scale: the G-MISS questionnaire. Health Qual Life Outcomes. 2017;15(1):1-13. doi:10.1186/s12955-017-0608-x

8. Silverstein M. Analysis of medical screening and surveillance in 21 occupational safety and health administration standards: support for a generic medical surveillance standard. Am J Ind Med. 1994;26 (3):283-295. doi:10.1002/ajim.4700260303

9. New Straits Times. Hospitals should be more worship-friendly, says health DG; 2016. Retrieved July 14, 2019. Available from: https:// www.nst.com.my/news/2016/10/181641/hospitals-should-be-moreworship-friendly-says-health-dg. Accessed November 25, 2019.

10. Rahman MK, Zailani S, Musa G. The perceived role of Islamic medical care practice in hospital: the medical doctor's perspective. J Islam Mark. 2018b;9(1):2-18. doi:10.1108/JIMA-01-2016-0006

11. Zawawi K, Othman M. An overview of Shari'ah compliant healthcare services in Malaysia. Malaysian J Consum Fam Econ. 2018;3 (1):91-100.

12. Malaysia Standard. MS1900:2014 Shariah-based quality management systems-requirements with guidance. Department of Standard Malaysia. Ministry of Science, Technology and Innovation, SIRIM Berhad; 2014. Issue date January 12, 2018. Retrieved from 14, 2019. Available from: https://www.academia.edu/26927157/MS_1900_ 2014_Shariahbased_Quality_Management_Systems-_Requirements_ with_guidance. Accessed December 29, 2019.

13. Rahman MK, Zailani S. The effectiveness and outcomes of the Muslim-friendly medical tourism supply chain. J Islam Mark. 2017;8(4):732-752. doi:10.1108/JIMA-11-2015-0082

14. Rahman MK, Zailani S. Understanding Muslim medical tourists' perception towards Islamic friendly hospital. $J$ Invest Manage. 2016;5(6):206-213.

15. International Insurance. Understanding Malaysia's healthcare system; 2021. Available from: https://www.internationalinsurance.com/ health/systems/malaysia.php. Accessed October 10, 2021.

16. Rahman M, Moghavvemi S, Thirumoorthi T, Rahman MK. The impact of tourists' perceptions on halal tourism destination: a structural model analysis. Tour Rev. 2020;75(3):575-594. doi:10.1108/TR-05-2019-0182

17. Rahman MK, Zailani S, Musa G. Tourists' satisfaction and loyalty intention at Shariah compliant private hospitals in Malaysia. Int $J$ Tour Sci. 2018a;18(4):295-311. doi:10.1080/15980 634.2018.1555605

18. Oliver RL. A cognitive model of the antecedents and consequences of satisfaction decisions. J Mark Res. 1980;17(4):460-469. doi: $10.1177 / 002224378001700405$

19. Parasuraman A, Zeithaml VA, Berry LL. A conceptual model of services quality and its implication for future research. $J$ Mark. 1985;49(5):41-50. doi:10.1177/002224298504900403
20. Abdelkader AA. Measuring service quality of the Muslim friendly hotels in England and its impact on behavioural intention. Int $J$ Customer Relatsh Mark Manage. 2015;6(3):1-24. doi:10.4018/IJCRMM.2015070101

21. Rahman MK, Zailani S, Musa G. Tapping into the emerging Muslim-friendly medical tourism market: evidence from Malaysia. J Islam Mark. 2017;8(4):514-532. doi:10.1108/JIMA-02-2016-0014

22. Carayon P, Wetterneck TB, Rivera-Rodriguez AJ, et al. Human factors systems approach to healthcare quality and patient safety. Appl Ergon. 2014;45(1):14-25. doi:10.1016/j.apergo.2013.04.023

23. Radnor ZJ, Holweg M, Waring J. Lean in healthcare: the unfilled promise? Soc Sci Med. 2012;74(3):364-371. doi:10.1016/j. socscimed.2011.02.011

24. Toussaint J. Writing the new playbook for US health care: lessons from Wisconsin. Health Aff. 2009;28(5):1343-1350. doi:10.1377/ hlthaff.28.5.1343

25. Holden R. Cognitive performance-altering effects of electronic medical records: an application of the human factors paradigm for patient safety. Cogn Technol Work. 2011a;13(1):11-29. doi:10.1007/s10111010-0141-8

26. Holden R. Lean thinking in emergency departments: a critical review. Ann Emerg Med. 2011b;57(3):265-278. doi:10.1016/j.annemerg med.2010.08.001

27. Lyu H, Wick EC, Housman M, Freischlag JA, Makary MA. Patient satisfaction as a possible indicator of quality surgical care. AMA Surg. 2013;148(4):362-367.

28. Tsai TC, Orav JE, Jha AK. Patient satisfaction and quality of surgical care in US hospitals. Ann Surg. 2015;261(1):2-8. doi:10.1097/ SLA.0000000000000765

29. Sower V, Duffy J, Kilbourne W, Kohers G, Jones P. The dimensions of service quality for hospitals: development and use of the KQCAH scale. Health Care Manage Rev. 2001;26(2):47-59. doi:10.1097/ 00004010-200104000-00005

30. Webster TR, Mantopoulos J, Jackson E, et al. A brief questionnaire for assessing patient healthcare experiences in low-income settings. Int J Qual Health Care. 2011;23(3):258-268. doi:10.1093/intqhe/mzr019

31. Nurunnabi M, Islam SK. Accountability in the Bangladeshi privatized healthcare sector. Int J Health Care Qual Assur. 2012;25 (7):625-644. doi:10.1108/09526861211261226

32. Alhassan RK, Duku SO, Janssens W, et al. Comparison of perceived and technical healthcare quality in primary health facilities: implications for a sustainable national health insurance scheme in Ghana. PLoS One. 2015;10(10):1-19. doi:10.1371/journal.pone.0140109

33. Marković $\mathrm{S}$, Lončarić $\mathrm{D}$, Lončarić $\mathrm{D}$. Service quality and customer satisfaction in the health care industry-towards health tourism market. Tour Hosp Manag. 2014;20(2):155-170. doi:10.20867/thm.20.2.1

34. Dagger TS, Sweeney JC, Johnson LW. A hierarchical model of health service quality: scale development and investigation of an integrated model. J Ser Res. 2007;10(2):123-142. doi:10.1177/1094670507309594

35. Flannelly KJ, Weaver AJ, Handzo GF, Smith WJ. A national survey of health care administrators' views on the importance of various chaplain roles. J Pastoral Care Counsel. 2005;59(1-2):87-96. doi: $10.1177 / 154230500505900109$

36. Shafaei F. The relationship between involvement with travelling to Islamic destinations and Islamic brand equity: a case of Muslim tourists in Malaysia. Asia Pac J Tour Res. 2016;22(3):255-271. doi:10.1080/10941665.2016.1232741

37. Vaus D. Survey in Social Research. 6th ed. New York: Routledge, Tylor \& Francis Group; 2014.

38. Ahmed V, Tezel A, Aziz Z, Sibley M. The future of big data in facilities management: opportunities and challenges. Facilities. 2017;35(13/14):725-745. doi:10.1108/F-06-2016-0064

39. Faul F, Erdfelder E, Buchner A, Lang AG. Statistical power analyses using G*Power 3.1: tests for correlation and regression analyses. Behav Res Methods. 2009;4(4):1149-1160. doi:10.3758/BRM.4 1.4.1149 
40. Chin WW. PLS-Graph User's Guide Version 3.0. Soft Modelling Inc. Houston, TX; 2001.

41. Sekaran U, Bougie R. Research Method for Business: A Skill Building Approach. London: John Wiley\& Sons; 2011.

42. Hair JF, Risher JJ, Sarstedt M, Ringle CM. When to use and how to report the results of PLS-SEM. Eur Bus Rev. 2019;31(1):2-24. doi:10.1108/EBR-11-2018-0203

43. Bourgeois S, Prater E, Slinkman C. The impact of information technology across small, medium and large hospitals. In: Tan J, editor. New Technologies for Advancing Healthcare and Clinical Practices. Hershey, PA, USA: IGI Global; 2011:347-361.

44. Byrne BM. Structural Equation Modeling with AMOS: Basic Concepts, Applications, and Programming. Routledge; 2013.

45. Thungjaroenkul P, Cummings GG, Tate K. Testing the social cognitive career theory in Thai nurses' interest to become nurse educators: a structural equation modeling analysis. Nurse Educ Today. 2016;44:151-156. doi:10.1016/j.nedt.2016.05.027

46. Ahmed S, Mohiuddin M, Rahman M, Tarique KM, Azim M. The impact of Islamic Shariah compliance on customer satisfaction in Islamic banking services: mediating role of service quality. $J$ Islam Mark. 2021. doi:10.1108/JIMA-11-2020-0346

47. Samori Z, Rahman FA, Zahari MS. Conceptual framework for Shari'ah governance with special reference to the Muslim friendly hotel sector in Malaysia. In Country Experiences in Economic Development, Management and Entrepreneurship: Proceedings of the 17th Eurasia Business and Economics Society Conference; Springer International Publishing; 2017:717-731.

48. Jeaheng Y, Al-Ansi A, Han H. Impacts of halal-friendly services, facilities, and food and beverages on Muslim travelers' perceptions of service quality attributes, perceived price, satisfaction, trust, and loyalty. J Hosp Mark Manage. 2020;29(7):787-811. doi:10.1080/ 19368623.2020.1715317

49. Tripathi K, Dong J, Mishkin BF, Feuerstein JD. Patient preference and adherence to aminosalicylates for the treatment of ulcerative colitis. Clin Exp Gastroenterol. 2021;14:343-351. doi:10.2147/ CEG.S237653

50. Benzimra M, Bonnamour B, Duracinsky M, et al. Real-life experience of quality of life, treatment satisfaction, and adherence in patients receiving oral anticoagulants for atrial fibrillation. Patient Prefer Adherence. 2018;12:79-87. doi:10.2147/PPA.S131158

51. Celik GO. The relationship between patient satisfaction and emotional intelligence skills of nurses working in surgical clinics. Patient Prefer Adherence. 2017;11:1363-1367. doi:10.2147/PPA.S136185
52. Budiwan V. The understanding of Indonesian patients of hospital service quality in Singapore. Procedia Soc Behav Sci. 2016;224:176-183. doi:10.1016/j.sbspro.2016.05.436

53. Taibanguay N, Chaiamnuay S, Asavatanabodee P, Narongroeknawin P. Effect of patient education on medication adherence of patients with rheumatoid arthritis: a randomized controlled trial. Patient Prefer Adherence. 2019;13:119-129. doi:10.2147/PPA.S192008

54. Rose RC, Uli J, Abdul M, Looi NK. Hospital service quality: a managerial challenge. Int $J$ Health Care Qual Assur. 2004;17 (3):146-159. doi:10.1108/09526860410532784

55. Zullig LL, Blalock DV, Dougherty S, et al. The new landscape of medication adherence improvement: where population health science meets precision medicine. Patient Prefer Adherence. 2018;12:1225-1230. doi:10.2147/PPA.S165404

56. Sim R, Lee SWH. Patient preference and satisfaction with the use of telemedicine for glycemic control in patients with type 2 diabetes: a review. Patient Prefer Adherence. 2021;15:283-298. doi:10.2147/ PPA.S271449

57. Kamra V, Singh H, De Kumar K. Factors affecting patient satisfaction: an exploratory study for quality management in the health-care sector. Total Qual Manag Bus Excell. 2016;27(9-10):1013-1027. doi:10.1080/14783363.2015.1057488

58. Akbolat M, Sezer C, Ünal Ö, Amarat M. The mediating role of patient satisfaction in the effect of patient visit experiences on word-of-mouth intention. Health Mark Q. 2021;38(1):12-22. doi:10.1080/07359683.2021.1947080

59. Dogra AK, Sharma SK. Effect of effective patient communication and customer orientation on service quality leading to patient satisfaction: a study of multi-specialty hospitals of North India. Int $J$ Manag Pract. 2021;14(3):368-385. doi:10.1504/ IJMP.2021.115097

60. Zhang J, Zhou F, Ge X, et al. Reliability and validity of an indicator system used to evaluate outpatient and inpatient satisfaction in Chinese hospitals. Patient Prefer Adherence. 2018;12:2527-2536. doi:10.2147/PPA.S186722

61. Zarei E, Arab M, Tabatabaei SMG, Rashidian A, Khabiri R. Understanding patients' behavioral intentions: evidence from Iran's private hospitals industry. $J$ Health Organ Manag. 2014;28 (6):795-810. doi:10.1108/JHOM-11-2012-0218

62. Wu Q, Amporfro DA, Boah M, et al. Patients satisfaction with healthcare delivery in Ghana. BMC Health Serv Res. 2021;21 (1):1-13.

\section{Publish your work in this journal}

Patient Preference and Adherence is an international, peer-reviewed, open access journal that focusing on the growing importance of patient preference and adherence throughout the therapeutic continuum. Patient satisfaction, acceptability, quality of life, compliance, persistence and their role in developing new therapeutic modalities and compounds to optimize clinical outcomes for existing disease states are major areas of interest for the journal. This journal has been accepted for indexing on PubMed Central. The manuscript management system is completely online and includes a very quick and fair peer-review system, which is all easy to use. Visit http:// www.dovepress.com/testimonials.php to read real quotes from published authors. 